\title{
Nipple-Sparing Mastectomy via Inframammary Fold: Reconstructive Red Flags
}

\author{
Umbareen Mahmood $^{1}$, Jessica Suber ${ }^{1}$, Ronit Zadikany ${ }^{1}$, Brian Kellogg ${ }^{1}$, William Fulp ${ }^{2}$, Christine Laronga ${ }^{3}$, \\ Deniz Dayicioglu ${ }^{1} \&$ Paul Smith ${ }^{1}$ \\ ${ }^{1}$ Division of Plastic Surgery, Department of Surgery, University of South Florida Morsani College of Medicine, \\ Tampa, FL, United States \\ ${ }^{2}$ Biostatistics, Moffitt Cancer Center, Tampa, FL, United States \\ ${ }^{3}$ Comprehensive Breast Program, Department of Women's Oncology, Moffitt Cancer Center, Tampa, FL, \\ United States \\ Correspondence: Umbareen Mahmood, Division of Plastic Surgery, Department of Surgery, University of South \\ Florida Morsani College of Medicine, Tampa, FL, United States. E-mail: umbarm@gmail.com
}

Received: March 23, 2016 Accepted: April 22, 2016 Online Published: April 26, 2016

doi:10.5539/cco.v5n1p102 URL: http://dx.doi.org/10.5539/cco.v5n1p102

\begin{abstract}
Background: Nipple-sparing mastectomy (NSM) is a technically feasible and oncologically sound option for patients who meet eligibility criteria. Inframammary fold (IMF) incision results in a well-hidden scar and enhanced final aesthetic result. While oncologic eligibility criteria have been well established, reconstructive criteria are less defined. We report Moffitt Cancer Center's (MCC) outcomes with IMF incision for NSM and immediate reconstruction, and factors associated with increased complication rate.
\end{abstract}

Methods: IRB approved retrospective cohort study of patients who underwent NSM through an IMF approach with immediate reconstruction at MCC from 2006-2013 was conducted. Analysis included patient demographics, tumor characteristics, ancillary treatment, reconstructive method, and nipple and skin flap necrosis. A literature review was performed to compare outcomes with other types of incisions.

Results: 115 patients met inclusion criteria, representing 199 breasts. The average age was 48.1 (range 18-74). The two main complication categories evaluated were nipple necrosis $(8 \%)$ and skin flap necrosis $(10.6 \%)$. Older age demonstrated a significant relationship with skin flap necrosis $(p=0.0155)$ and overall complications $(\mathrm{p}=0.0492)$. Complication rate was significantly higher in the cancer side vs. prophylactic side in patients who underwent bilateral mastectomies $(\mathrm{p}=0.0088)$. Factors with trends related to increased skin flap necrosis included increased mastectomy specimen weight $(\mathrm{p}=0.0704)$, smoking $(\mathrm{p}=0.0726)$, and significant comorbidities $(\mathrm{p}=0.0665)$.

Conclusion: Our institution's results substantiate that NSM through an IMF approach with immediate reconstruction is a viable option. Recognized risk factors such as age, laterality, breast weight, smoking history, and comorbidities associated with increased complications should be considered when determining patient selection for reconstruction.

Keywords: breast cancer; inframammary; mastectomy; nipple-sparing; reconstruction

\section{Introduction}

Nipple-sparing mastectomy (NSM) continues to gain popularity as a viable option for prophylactic and therapeutic surgical treatment of breast cancer in patients who meet inclusion criteria. Data from numerous series of NSM demonstrate that it is oncologically appropriate in patients with tumors that are at least $2 \mathrm{~cm}$ away from the base of the nipple, less than $3 \mathrm{~cm}$ in diameter, no clinical lymphadenopathy with negative sentinel node, no skin involvement, non- inflammatory breast cancer, no clinical nipple signs (retraction, bleeding, discharge, or pruritus), a unifocal tumor, and with a negative pathological section from intraoperative sampling of the nipple base (Spear, Hannan, Willey, \& Cocilovo, 2009; Vlajcic, Zic, Stanec, Lambasa, Petrovecki, \& Stanec, 2005; Laronga, Kemp, Johnston, Robb, \& Singletary, 1999; Gerber, Krause, Dieterich, Kundt, \& Reimer, 2009; Benediktsson \& Perbeck, 2008; Stolier \& Wang, 2008; Lagios, Gates, Westdahl, Richards, \& Alpert, 1979; Gulben, Yildirim, \& Berberoglu, 2009; Verma, Kumar, \& Joshi, 1997; Smith, Payne, \& Carney, 1976). With 
careful patient selection and direct sampling/pathological evaluation of the sub-areolar tissue intraoperatively, NSM can be safely performed within oncological parameters.

Nipple-areola complex sparing mastectomy with IMF approach has been demonstrated to have lower nipple and skin necrosis rates compared to other types of incisions, with the additional advantage of a well-hidden scar. Our objective was to identify patient and breast specific variables associated with complications of skin flap and nipple necrosis in patients undergoing nipple-sparing mastectomy via an inframammary fold incision with immediate breast reconstruction. These findings aim to assist in establishing reconstructive criteria to further guide appropriate patient selection.

\section{Patients and Methods}

\subsection{Data Collection}

With approval by Moffitt Cancer Center (MCC) and the University of South Florida Institutional Review Board, we conducted a retrospective cohort study of patients who underwent a unilateral or bilateral nipple-sparing mastectomy through an inframammary incision with immediate breast reconstruction at MCC between 2006 and 2013. Standardized data abstraction forms created by the breast department were utilized to ensure thorough data collection for all patients. Follow-up ranged from one to seven years and included clinic visits in which there was evaluation by the attending plastic surgeon. Few patients were lost to follow-up prior to one year post-operatively, and they were excluded from the study. The primary author reviewed 121 charts, and data was crosschecked by the co-authors to minimize data extraction errors. Inclusion criteria for nipple sparing mastectomy through an inframammary incision was based on MCC guidelines (Figure 1). Study size was

\begin{tabular}{|c|c|c|c|}
\hline $\begin{array}{l}\text { Inclusion Criteria: Patients must meet all of the following criteria. Yes must be marked } \\
\text { for all Inclusion. N/A can only be marked for those not blacked out. }\end{array}$ & Yes & No & $\mathbf{N} / \mathbf{A}$ \\
\hline \multicolumn{4}{|c|}{$\begin{array}{l}\text { All patients who will be surgically treated for breast cancer at Moffitt Cancer Center (MCC) with a mastectomy and } \\
\text { immediate reconstruction will be eligible for this study if all of the following criteria are met: }\end{array}$} \\
\hline \multicolumn{4}{|c|}{ 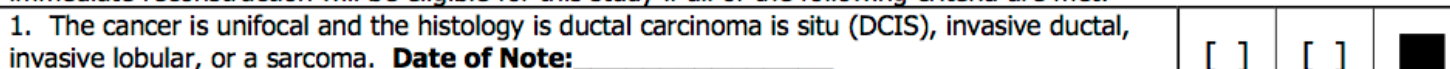 } \\
\hline \multicolumn{4}{|l|}{$\begin{array}{l}\text { 2. The area of cancer (histologies aforementioned), is } 5 \mathrm{~cm} \text {. or smaller based on pre-operative } \\
\text { breast imaging. Date of Note: }\end{array}$} \\
\hline \multicolumn{4}{|l|}{$\begin{array}{l}\text { 3. The tumor margin is greater than } 2 \mathrm{~cm} \text { from the areola edge based radially and } 2 \mathrm{~cm} \text { from } \\
\text { the posterior margin of the nipple-areola base based on pre-operative breast imaging. } \\
\text { Date of Note: }\end{array}$} \\
\hline \multicolumn{4}{|c|}{$\begin{array}{l}\text { 4. Clinically the patient is lymph node-negative and having a sentinel lymph node biopsy at the } \\
\text { time of the mastectomy on the cancer side (not required on a prophylactic mastectomy). } \\
\text { Date of Note: }\end{array}$} \\
\hline \multicolumn{4}{|c|}{$\begin{array}{l}\text { Note: All patients who will have a prophylactic mastectomy (unilateral or bilateral) for risk reduction will be eligible for } \\
\text { a nipple-sparing mastectomy of the breast without cancer. }\end{array}$} \\
\hline $\begin{array}{l}\text { Exclusion Criteria: Any of the following is a criterion for exclusion from the study: } \\
\text { No must be marked for all exclusion. N/A only for those not blacked out. }\end{array}$ & Yes & No & \\
\hline $\begin{array}{l}\text { 1. Patients under the age of } 18 \text { and patients over the age of } 85 \text { at the time of surgery. } \\
\text { Date of Birth: }\end{array}$ & & & \\
\hline $\begin{array}{l}\text { 2. Extensive Ductal Carcinoma In Situ greater than } 5 \mathrm{~cm} \text { in total area. } \\
\text { Date of Note: }\end{array}$ & & & \\
\hline $\begin{array}{l}\text { 3. Previous history of irradiation to the breast area (i.e. Mantle radiation for lymphoma) } \\
\text { Date of Note: }\end{array}$ & & & \\
\hline $\begin{array}{l}\text { 4. Previous history of nipple-areola surgery (duct excision, circumareolar incisions) within last } 3 \\
\text { years. Date of Note: }\end{array}$ & & & \\
\hline $\begin{array}{l}\text { 5. The invasive cancer is greater than } 5 \mathrm{~cm} \text { in size, is multicentric, is within } 2 \mathrm{~cm} \text { from the areola } \\
\text { margin or is within } 2 \mathrm{~cm} \text { from the posterior aspect of the nipple-areola base. } \\
\text { Date of Note: }\end{array}$ & & & \\
\hline $\begin{array}{l}\text { 6. Clinically suspicious axillary lymph nodes on palpation or by fine needle aspiration. } \\
\text { Date of Note: }\end{array}$ & & & \\
\hline 7. History of smoking within 6 weeks of intended surgery. Date of Note: & & & \\
\hline 8. Obesity (defined as BMI of greater than 35). Date of Note: & & & \\
\hline 9. Not a candidate for immediate breast reconstruction. Date of Note: & & & \\
\hline $\begin{array}{l}\text { 10. Not a candidate for nipple sparing mastectomy due to breast size is }>700 \text { grams or } \\
\text { significant contour abnormalities of the nipple-areola complex itself. Date of Note: }\end{array}$ & & & \\
\hline
\end{tabular}

Figure 1. Moffitt Cancer Center Nipple-Sparing Mastectomy Eligibility Checklist 
established by identifying patients who underwent the procedure of interest within the designated period, met oncologic eligibility criteria, and had sufficient follow-up. These explicit criteria determined patient selection for inclusion in the retrospective chart review.

The following data was extracted for each patient: age, race, BMI, smoking history, comorbidities, history of chemotherapy or radiation therapy, previous lumpectomy, unilateral or bilateral cancer, unilateral or bilateral mastectomy, excised breast weight, type of reconstruction, tissue expander fill volume, implant volume, skin flap necrosis, nipple necrosis, and any complication. All predictors were measured at the time of surgery, and complications were assessed as occurring within the sixty-day postoperative period. Primary outcome variable of interest was overall complication, particularly skin flap and/or nipple necrosis.

Potential confounding factors include previous lumpectomy and mastectomy technique, for example, scissor versus electrocautery dissection. Factors considered potential effect modifiers were age at time of surgery, comorbidities, social history, breast volume, and size of expander/implant, all of which were included in the statistical analysis. Sources of data for these variables were identified in the patient's chart; patient age, breast volume, and size of expander/implant were continuous quantitative data that did not need to be grouped. Qualitative variables including comorbidities, related treatments, and smoking and/or alcohol history were designated with a binary variable. We examined quantitative variables that could contribute to any complication, particularly those of skin flap and/or nipple necrosis, and grouped them according to patient or breast specific variables.

Potential sources of bias include discrepancy between observer assessments of skin flap or nipple necrosis. To minimize bias, patients who had reconstruction from non-primary MCC plastic surgeons were excluded, generally due to insufficient follow-up or non-standardized objective post-operative evaluation. The vast majority of patients had reconstruction performed by the senior author, and therefore pre and post-operative assessment of all patients was consistent. Furthermore, clinical documentation by all relevant providers (ie: attending surgeon, resident, nursing notes) was reviewed, and any mention of nipple or skin flap compromise from epidermolysis to full thickness loss was included and noted as a complication.

Standard breast markings made preoperatively included: midline, meridian, IMF, tangent from the inferior point of the IMF across the midline, dashed lines to denote $1 \mathrm{~cm}$ lateral from midline bilaterally, and dashed lines to mark the upper border of the breast mound. An 8-11 centimeter incision was made along the inframammary fold curving up laterally following the breast crease. Mastectomy was performed by the breast surgeon with either scissor or electrocautery dissection based on his/her preference, without use of tumescent infiltration. Fluorescent angiography or woods lamp assessment of the mastectomy skin flaps was not performed, as these modalities are not routinely employed at our facility for this procedure. Intraoperative nipple base samples were sent to pathology for frozen section evaluation, and axillary sentinel lymph node biopsy was performed in all patients with known breast cancer. Once the nipple base margins and sentinel node biopsies were confirmed negative for carcinoma, reconstruction was begun. Reconstruction was performed by one of two plastic surgeons, with the majority of cases performed by the senior author.

The main type of reconstruction was tissue expander reconstruction, with a small subset undergoing latissimus dorsi flap and tissue expander reconstruction. We favor total submuscular coverage in skin-sparing mastectomy followed by expander placement. The pectoralis major muscle was dissected laterally, creating a submuscular pocket equivalent to pre-measured base width size. The serratus anterior muscle or fascia was lifted off the anterior chest wall, the expander was inserted, and the muscles were reapproximated using 3.0 Vicryl interrupted suture. Expanders were then inflated with a variable amount of saline based on plastic surgeon discretion. Standard surgical technique included insertion of one 15 french Jackson-Pratt drain placed subcutaneously in each breast pocket, and secured with a 3.0 Nylon suture. The skin was closed in a layered fashion using 3.0 monofilament deep dermal sutures followed by a 4.0 monofilament running subcuticular closure. Post-operative course generally consisted of one to two days of routine inpatient hospital stay. Clinic follow-up was scheduled within five days following discharge, and removal of drains occurred when output of each drain was less than thirty milliliters for two consecutive twenty-four hour periods.

\subsection{Statistical Analysis}

Statistical analysis performed by the Biostatistics department at Moffitt Cancer Center included descriptive statistics for both patient and breast level variables. When comparing variables to overall complications or presence of skin flap or nipple necrosis, p-values were calculated using generalized linear model adjusting for correlation within patient ID, and are from separate single variable models. Six patients had missing data or inadequate follow-up; these individuals were representative of the original study sample, and due to the small 
number, they were excluded from the study. All p-values are two-sided, and considered statistically significant at the 0.05 level. All statistical analyses were performed using SAS (version 9.3; SAS Institute; Cary, NC).

\section{Results}

Of the 441 patients in the Moffitt Cancer Center breast surgery research database from 2006 to 2013, 121 patients had nipple-sparing mastectomy with immediate reconstruction. Among them, 115 patients were identified who met full inclusion criteria, representing 199 breasts. The mean $( \pm \mathrm{SD})$ age was $48.0 \pm 10.3$ years (range 18-74). One hundred patients underwent immediate breast reconstruction with tissue expander reconstruction, and nine patients underwent latissimus dorsi flap (LD) with tissue expander reconstruction. LD was performed in patients who had unilateral NSM to achieve optimal symmetry with the contralateral unaffected breast, patients who desired autologous reconstruction but were not candidates for, or opted against, use of abdominal tissue, and in patients with a history of radiation therapy. Routine use of single stage implants was not employed at our facility during this study. Average total tissue expander fill volume was $228.9 \mathrm{~mL}$ (range 50-700 $\mathrm{ml}$ ), and average final implant volume was $534.04 \mathrm{cc}$.

Acellular dermal matrix was not utilized in these patients due to adequate mastectomy tissue flap thickness and effective total muscular coverage of the expander. Radiation therapy was indicated as 'any radiation' or 'no radiation'; 23 patients received radiation, 92 patients did not. 14 of the 23 patients received adjuvant radiation therapy following mastectomy and 9 had a remote history of radiation following previous lumpectomy. The majority of patients had unilateral breast cancer and underwent bilateral NSM (Table 1). Any patient with positive nipple margins was ineligible for NSM and therefore excluded from the sample group. The potential confounding factor of previous lumpectomy was evaluated and was determined to have no statistical relationship with skin flap or nipple necrosis ( $p=0.2011$ and 0.7580 , respectively). The two main complications evaluated were skin flap and/or nipple necrosis. Our results demonstrated a $10.6 \%$ rate of skin flap necrosis, and $8 \%$ rate of nipple necrosis (Table 2). All objective flap or nipple-related complications ranging from epidermolysis or partial thickness loss treated with local wound care, to full-thickness loss necessitating reconstruction, were included in the calculation of necrosis.

Table 1. Patient specific variables

\begin{tabular}{ll}
\hline Variable & \multicolumn{1}{c}{ N; Mean (STD); Median [Range] } \\
\hline Age & $\mathrm{n}=115 ; 48.09(10.24) ; 48[18,74]$ \\
BMI & $\mathrm{n}=113 ; 22.77(2.47) ; 22.8[17,29.8]$ \\
\hline
\end{tabular}

\begin{tabular}{lll}
\hline \multicolumn{1}{c}{ Patient demographics } & \multicolumn{1}{c}{ Variable } & Percent \\
\hline Race & White & 88.70 \\
& Non-White & 11.30 \\
Ever Smoked & No & 74.78 \\
Any Co-morbidities & Yes & 25.22 \\
& No & 50.43 \\
Chemotherapy & Yes & 49.57 \\
\multirow{4}{*}{ Radiation } & No & 64.35 \\
\multirow{3}{*}{ Bilateral/Unilateral Cancer } & Yes & 35.65 \\
& No & 80.0 \\
& Yes & 20.0 \\
Bilateral/Unilateral NSM & None (prophylactic) & 8.70 \\
& Unilateral & 76.78 \\
Latissimus Dorsi Flap & Bilateral & 76.52 \\
& Unilateral & 23.47 \\
& No & 92.17 \\
& Yes & 7.83 \\
\hline
\end{tabular}


Table 2. Breast specific variables

\begin{tabular}{cc}
\hline Variable & N; Mean(STD); Median [Range] \\
\hline Breast weight & $\mathrm{n}=185 ; 373.99(167.75) ; 337.5[41,880]$ \\
\hline
\end{tabular}

\begin{tabular}{lll}
\hline \multicolumn{1}{c}{ Breast specific } & \multicolumn{1}{c}{ Variable } & Percent \\
\hline Breast Side & Left & 51.26 \\
& Right & 48.74 \\
Skin Flap Necrosis & No & 89.44 \\
& Yes & 10.55 \\
Nipple Necrosis & Yes & 8.04 \\
& No & 91.96 \\
Cancer Side & Cancer Side & 50.40 \\
& Non-Cancer Side & 49.60 \\
\hline
\end{tabular}

Table 3. Skin flap necrosis in relation to patient demographics

\begin{tabular}{lllr}
\hline \multirow{2}{*}{ Variable } & \multicolumn{2}{c}{ N; Mean(STD); Median [Range] } & \\
\cline { 2 - 4 } Age & $\mathrm{n}=178 ; 46.77(9.99) ; 47[18,74]$ & \multicolumn{1}{c}{ Nk Skin Flap Necrosis } & P Value \\
BMI & $\mathrm{n}=176 ; 22.78(2.56) ; 22.8[17,29.86 .58) ; 54[42,71]$ & $\mathrm{n}=21 ; 23.18(1.92) ; 22.7[20.6,27.5]$ & 0.0155 \\
Breast Weight & $\mathrm{n}=164 ; 366.4(169.2) ; 330.5[41,880]$ & $\mathrm{n}=21 ; 433.3(146.23) ; 437[225.7,765.5]$ & 0.3638 \\
TE Fill Amount & $\mathrm{n}=142 ; 227.53(125.39) ; 200[50,680]$ & $\mathrm{n}=17 ; 240.59(144.33) ; 200[100,700]$ & 0.5764 \\
\hline
\end{tabular}

\begin{tabular}{|c|c|c|c|c|}
\hline \multirow[b]{2}{*}{ Variable } & & \multicolumn{2}{|c|}{ N (\%) } & \multirow[b]{2}{*}{ P Value } \\
\hline & & No Skin Flap Necrosis & Skin Flap Necrosis & \\
\hline \multirow[t]{2}{*}{ Ever Smoked } & No & $137(93.2 \%)$ & $10(6.8 \%)$ & 0.0726 \\
\hline & Yes & $41(78.8 \%)$ & $11(21.2 \%)$ & \\
\hline \multirow[t]{2}{*}{ Any Co-morbidities } & No & $96(94.1 \%)$ & $6(5.9 \%)$ & 0.0665 \\
\hline & Yes & $82(84.5 \%)$ & $15(15.5 \%)$ & \\
\hline \multirow{3}{*}{$\begin{array}{l}\text { Bilateral/Unilateral } \\
\text { Cancer }\end{array}$} & Bilateral & $17(94.4 \%)$ & $1(5.6 \%)$ & 0.5440 \\
\hline & None (prophylactic) & $26(86.7 \%)$ & $4(13.3 \%)$ & \\
\hline & Unilateral & $135(89.4 \%)$ & $16(10.6 \%)$ & \\
\hline \multirow[t]{2}{*}{ Previous Lumpectomy } & No & $127(87.6 \%)$ & $18(12.4 \%)$ & 0.2011 \\
\hline & Yes & $51(94.4 \%)$ & $3(5.6 \%)$ & \\
\hline \multirow[t]{2}{*}{ Chemotherapy } & No & $112(87.5 \%)$ & $16(12.5 \%)$ & 0.3823 \\
\hline & Yes & $66(93 \%)$ & $5(7 \%)$ & \\
\hline \multirow[t]{2}{*}{ Radiation } & No & $140(88.6 \%)$ & $18(11.4 \%)$ & 0.5288 \\
\hline & Yes & $38(92.7 \%)$ & $3(7.3 \%)$ & \\
\hline \multirow{2}{*}{$\begin{array}{l}\text { Bilateral/Unilateral } \\
\text { NSM }\end{array}$} & Bilateral & $156(90.7 \%)$ & $16(9.3 \%)$ & 0.2339 \\
\hline & Unilateral & $21(80.8 \%)$ & $5(19.2 \%)$ & \\
\hline \multirow[t]{2}{*}{ TE Placed } & No & $17(89.5 \%)$ & $2(10.5 \%)$ & 0.7907 \\
\hline & Yes & $161(89.4 \%)$ & $19(10.6 \%)$ & \\
\hline \multirow[t]{2}{*}{ Cancer Side } & Cancer Side & $57(90.5 \%)$ & $6(9.5 \%)$ & 0.3204 \\
\hline & Non-Cancer Side & $57(91.9 \%)$ & $5(8.1 \%)$ & \\
\hline
\end{tabular}


Table 4. Nipple necrosis in relation to patient demographics

\begin{tabular}{llll}
\hline \multirow{2}{*}{ Variable } & \multicolumn{2}{c}{ N; Mean(STD); Median [Range] } & \\
\cline { 2 - 4 } Age & $\mathrm{n}=17 ; 45.41(7.3) ; 45[33,60]$ & $\mathrm{n}=182 ; 47.71(10.28) ; 47[18,74]$ & Nipple Survival \\
BMI & $\mathrm{n}=16 ; 23.92(2.73) ; 24.27[19.8,26.7]$ & $\mathrm{n}=181 ; 22.72(2.46) ; 22.7[17,29.8]$ & 0.4446 \\
Breast WT & $\mathrm{n}=15 ; 393.2(123.56) ; 374.1[209,589.9]$ & $\mathrm{n}=170 ; 372.3(171.28) ; 333.7[41,880]$ & 0.5413 \\
TE Fill Amount & $\mathrm{n}=13 ; 230.77(138.71) ; 250[80,530]$ & $\mathrm{n}=146 ; 228.76(126.54) ; 200[50,700]$ & 0.9650 \\
\hline
\end{tabular}

\begin{tabular}{|c|c|c|c|c|}
\hline \multirow[b]{2}{*}{ Variable } & & \multicolumn{2}{|c|}{ N (\%) } & \multirow[b]{2}{*}{ P Value } \\
\hline & & No Nipple Survival & Nipple Survival & \\
\hline \multirow[t]{2}{*}{ Any Co-morbidities } & No & $8(7.8 \%)$ & $94(92.2 \%)$ & 0.6541 \\
\hline & Yes & $9(9.3 \%)$ & $88(90.7 \%)$ & \\
\hline \multirow[t]{3}{*}{ Bilateral/Unilateral Cancer } & Bilateral & $4(22.2 \%)$ & $14(77.8 \%)$ & 0.3961 \\
\hline & None (prophylactic) & $4(13.3 \%)$ & $26(86.7 \%)$ & \\
\hline & Unilateral & $9(6 \%)$ & $142(94 \%)$ & \\
\hline \multirow[t]{2}{*}{ Previous Lumpectomy } & No & $12(8.3 \%)$ & $133(91.7 \%)$ & 0.7580 \\
\hline & Yes & $5(9.3 \%)$ & $49(90.7 \%)$ & \\
\hline \multirow[t]{2}{*}{ Chemotherapy } & No & $12(9.4 \%)$ & $116(90.6 \%)$ & 0.5129 \\
\hline & Yes & $5(7 \%)$ & $66(93 \%)$ & \\
\hline \multirow[t]{2}{*}{ Radiation } & No & $11(7 \%)$ & $147(93 \%)$ & 0.2321 \\
\hline & Yes & $6(14.6 \%)$ & $35(85.4 \%)$ & \\
\hline \multirow[t]{2}{*}{ Bilateral/Unilateral NSM } & Bilateral & $15(8.7 \%)$ & $157(91.3 \%)$ & 0.8672 \\
\hline & Unilateral & $2(7.7 \%)$ & $24(92.3 \%)$ & \\
\hline \multirow[t]{2}{*}{ TE Placed } & No & $1(5.3 \%)$ & $18(94.7 \%)$ & 0.7352 \\
\hline & Yes & $16(8.9 \%)$ & $164(91.1 \%)$ & \\
\hline \multirow[t]{2}{*}{ Latissimus Dorsi Flap } & No & $15(8.2 \%)$ & $169(91.8 \%)$ & 0.4796 \\
\hline & Yes & $2(13.3 \%)$ & $13(86.7 \%)$ & \\
\hline \multirow[t]{2}{*}{ Cancer Side } & Cancer Side & $4(6.3 \%)$ & $59(93.7 \%)$ & 0.3243 \\
\hline & Non-Cancer Side & $2(3.2 \%)$ & $60(96.8 \%)$ & \\
\hline
\end{tabular}

Older age was found to have a significantly higher prevalence of skin flap necrosis; mean age of patients with necrosis was 53.9 years (range 42-71) compared to 46.8 years (range 18-74) of those that did not experience this complication $(\mathrm{p}=0.0155)$. A trend was noted between greater excised breast weight and frequency of skin flap necrosis $(p=0.0704)$. Among patients with skin flap necrosis, a higher percentage had a history of smoking $(21.2 \%$ vs. $6.8 \% ; p=0.0726)$ and other comorbidities such as hypertension and diabetes $(15.5 \%$ vs. $5.9 \% ; p=$ 0.0665) (Table 3). With regards to nipple necrosis, there were no identifiable trends (Table 4). Interestingly, our data demonstrated that patients who received adjuvant chemotherapy had a lower proportion of complications than those who did not $(p=0.0503)$. In patients who underwent bilateral mastectomies for unilateral cancer, there was a 1.5 times higher proportion of complications on the breast cancer side compared to the prophylactic side $(p=0.0088)$ (Table 5).

Pre-operative and post-operative photographs of three representative patients who each underwent bilateral nipple-sparing mastectomy via an IMF incision are illustrated in Figures 2-3. 
Table 5. Complication rates in relation to patient demographics

\begin{tabular}{lllr} 
& \multicolumn{3}{c}{ N; Mean(STD); Median [Range] } \\
\cline { 2 - 4 } Variable & \multicolumn{1}{c}{ No Complications } & \multicolumn{1}{c}{ Any Complication } & P Value \\
\hline Age & $\mathrm{n}=109 ; 45.9(10.13) ; 45[18,74]$ & $\mathrm{n}=90 ; 49.48(9.69) ; 49[18,71]$ & 0.0492 \\
BMI & $\mathrm{n}=108 ; 22.83(2.54) ; 22.85[17,29.8]$ & $\mathrm{n}=89 ; 22.8(2.46) ; 22.7[17.8,28.1]$ & 0.8639 \\
\hline
\end{tabular}

\begin{tabular}{|c|c|c|c|c|c|}
\hline \multirow[b]{2}{*}{ Variable } & & \multicolumn{3}{|c|}{$\mathbf{N}(\%)$} & \multirow[b]{2}{*}{ P Value } \\
\hline & & $\begin{array}{c}\text { Number of } \\
\text { patients }\end{array}$ & $\begin{array}{c}\text { No } \\
\text { Complications }\end{array}$ & $\begin{array}{c}\text { Any } \\
\text { Complication }\end{array}$ & \\
\hline \multirow[t]{2}{*}{ Ever Smoked } & No & $147(73.9 \%)$ & $84(57.1 \%)$ & $63(42.9 \%)$ & 0.2999 \\
\hline & Yes & $52(26.1 \%)$ & $25(48.1 \%)$ & $27(51.9 \%)$ & \\
\hline \multirow[t]{2}{*}{ Any Co-morbidities } & No & $102(51.3 \%)$ & $58(56.9 \%)$ & $44(43.1 \%)$ & 0.6988 \\
\hline & Yes & $97(48.7 \%)$ & $51(52.6 \%)$ & $46(47.4 \%)$ & \\
\hline \multirow[t]{2}{*}{ Previous Lumpectomy } & No & $145(72.9 \%)$ & $78(53.8 \%)$ & $67(46.2 \%)$ & 0.7646 \\
\hline & Yes & $54(27.1 \%)$ & $31(57.4 \%)$ & $23(42.6 \%)$ & \\
\hline \multirow[t]{2}{*}{ Chemotherapy } & No & $128(64.3 \%)$ & $62(48.4 \%)$ & $66(51.6 \%)$ & 0.0503 \\
\hline & Yes & $71(35.7 \%)$ & $47(66.2 \%)$ & $24(33.8 \%)$ & \\
\hline \multirow[t]{2}{*}{ Radiation } & No & $158(79.4 \%)$ & $90(57 \%)$ & $68(43 \%)$ & 0.2653 \\
\hline & Yes & $41(20.6 \%)$ & $19(46.3 \%)$ & $22(53.7 \%)$ & \\
\hline \multirow[t]{2}{*}{ Bilateral/Unilateral NSM } & Bilateral & $172(86.9 \%)$ & $91(52.9 \%)$ & $81(47.1 \%)$ & 0.2527 \\
\hline & Unilateral & $26(13.1 \%)$ & $17(65.4 \%)$ & $9(34.6 \%)$ & \\
\hline \multirow[t]{2}{*}{ Cancer Side } & Cancer Side & $63(50.4 \%)$ & $32(50.8 \%)$ & $31(49.2 \%)$ & 0.0088 \\
\hline & Non-Cancer Side & $62(49.6 \%)$ & $41(66.1 \%)$ & $21(33.9 \%)$ & \\
\hline
\end{tabular}

A.
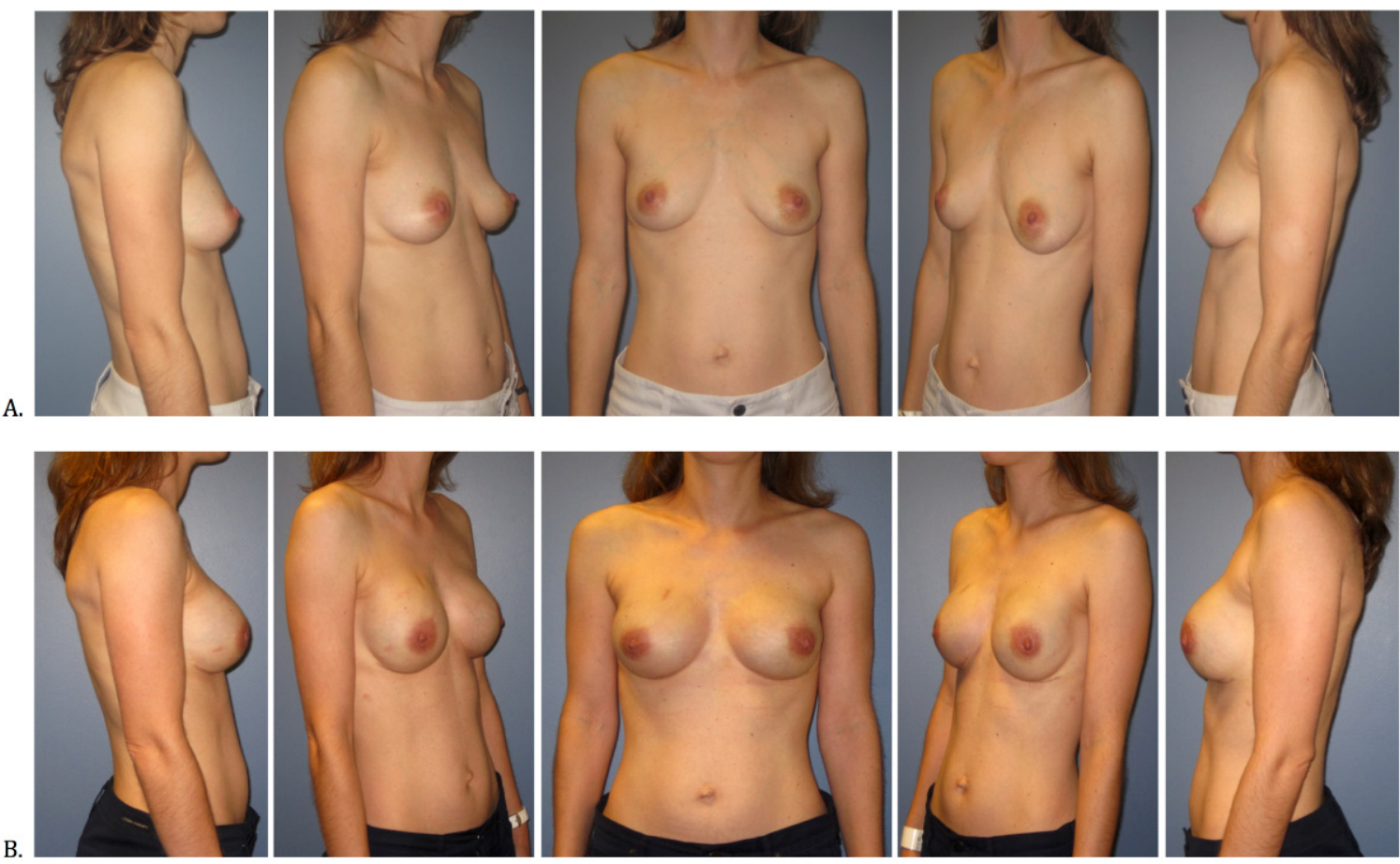

Figure 2. 37 year old female with strong family history of breast cancer. A. pre-operative; B. post-operative after prophylactic bilateral NSM via IMF incision with tissue expander and silicone breast implant reconstruction 

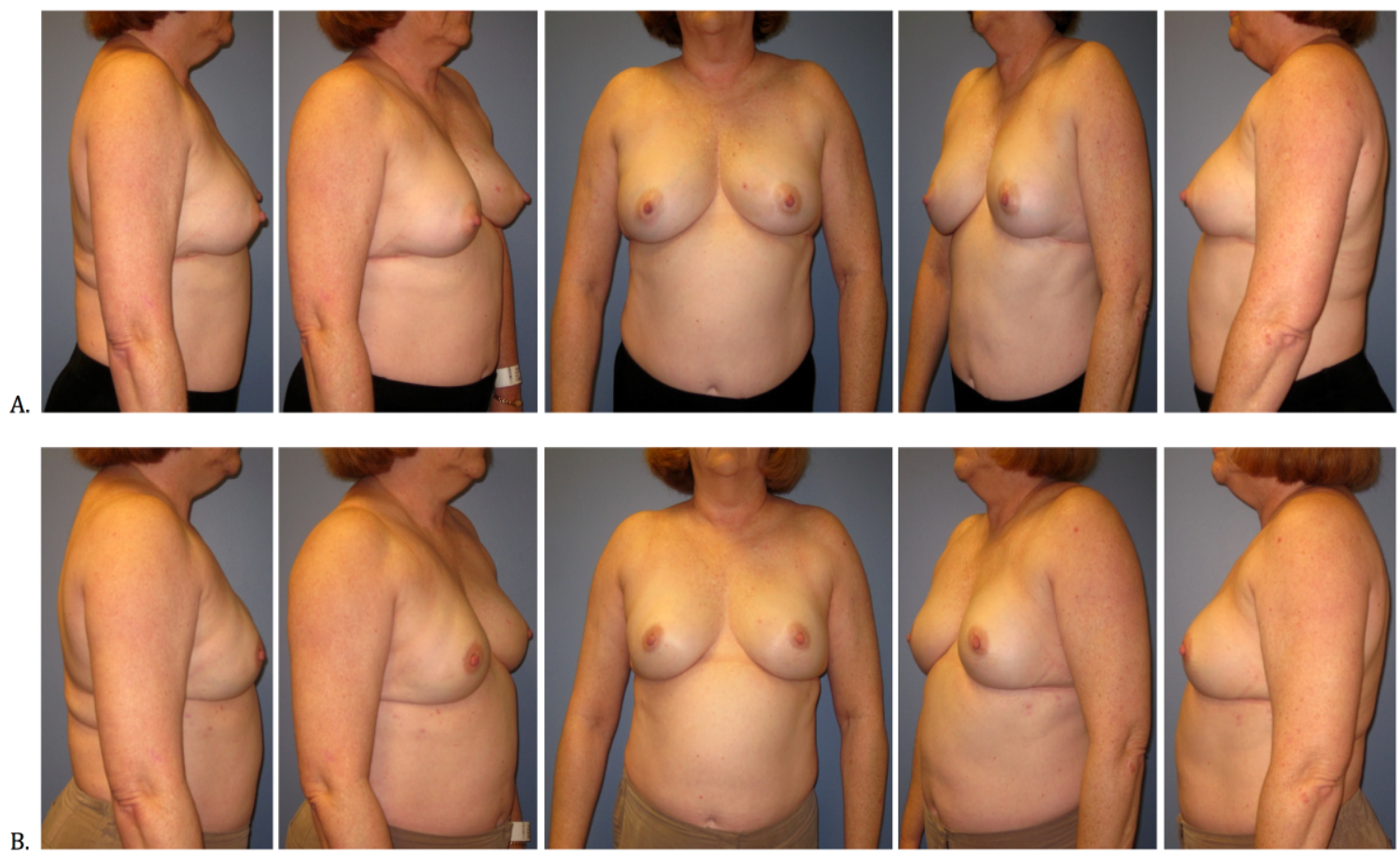

Figure 3. 57 year old female with left DCIS. A. pre-operative; B. post-operative after bilateral NSM via IMF incision with tissue expander and silicone breast implant reconstruction

\section{Discussion}

Long-term follow-up in breast cancer survivorship has demonstrated that NSM is as oncologically sound as other types of mastectomy. Secondary to oncologic criteria for NSM is reconstructive criteria, with a focus on factors associated with skin flap and nipple necrosis. While there are less objective measures, basic guidelines that have been proposed include small to moderate breast size, minimal to moderate ptosis, and satisfactory skin quality (Sacchini et al., 2006; Caruso et al., 2006). Other suggested considerations for reconstructive criteria include appropriate incision placement, employing caution in patients with large breasts with previous scars, patients with prior breast/chest radiation therapy, and in individuals who are smokers or diabetics (Salgarello, Visconti, \& Barone-Adesi, 2010). Our results demonstrate that nipple-sparing mastectomy via IMF incision is an efficient procedure with a prevalence of $10.6 \%$ skin flap necrosis and $8 \%$ nipple necrosis. This approach has the lowest complication in patients who are younger, non-smokers, smaller breast sized, generally healthy with no or minimal medical comorbidities, and on the prophylactic mastectomy breast.

Two of the main complications of immediate reconstruction following NSM are skin flap and nipple necrosis. While extent of resection and type of breast reconstruction contribute to the risk of complication, incision placement has a profound effect, particularly with regard to nipple necrosis. Our results of $10.6 \%$ skin flap necrosis and 8\% NAC necrosis are lower compared to non-IMF incisions reported in other studies, and our results are consistent with those reported in the literature for IMF incisions. Other surgical approaches to NSM that have been described include periareolar, inframammary, vertical, transareolar, radial, and an incision placed at the site of a previous scar.

A systematic review of English articles using the PubMed, MEDLINE, Ovid, Cochrane databases, and reference lists of relevant articles was performed. We used the following key terms to search all databases: nipple-sparing mastectomy, inframammary fold, immediate reconstruction, skin flap necrosis, nipple necrosis, and reconstructive criteria. The literature reflects a wide range of nipple-areolar complex necrosis rates between 0-48\% (Salgarello et al., 2010; Rusby, Smith, \& Gui, 2010; Wijayanayagam, Kumar, Foster, \& Esserman, 2008; Petit et al., 2006; Bistoni, Rulli, Izzo, Noya, Alfano, \& Barberini, 2006; de Alcantara Filho, Capko, Barry, Morrow, Pusic, \& Sacchini, 2011; Harness, Vetter, \& Salibian, 2011; Jensen, Orringer, \& Giuliano, 2011; Margulies, Hochberg, Kepple, Henry-Tillman, Westbrook, \& Klimberg, 2005; Sacchini et al., 2006; Spear et al., 2011; Djohan et al., 2010; Crowe et al., 2004; Colwell et al., 2014; Salibian, Harness, \& Mowlds, 2013; Endara, Chen, Verma, Nahabedian, \& Spear, 2013). In their recent review of 113 cases of NSM with immediate breast 
reconstruction, Gould et al. (2013) found that their overall incidence of any (partial or total) nipple necrosis was $20 \%$ via a non-IMF approach. In a review of 64 NSM via various approaches, Wijayanayagam et al. noted a total NAC necrosis rate of $20 \%$, partial NAC necrosis $84 \%$, and total skin-sparing skin flap necrosis of $17 \%$. NSM via IMF incision had $0 \%$ necrosis, whereas NAC-crossing incisions had $81.8 \%$ partial necrosis, leading the authors to conclude that incisions spanning $>1 / 3$ of the NAC circumference likely compromised blood supply, resulting in nipple-areola skin necrosis (Wijayanayagam et al., 2008). Direct comparison of two cohorts of total skin-sparing mastectomies that differed in extent of NAC involved in the incision illustrated that periareolar incisions involving more than $30 \%$ of the circumference of the areola are at an increased risk of NAC necrosis, and along with other variables, adjusting the incision contributed to a significant reduction in nipple necrosis rates from $20 \%$ to $5 \%$ (Garwood et al., 2009). Furthermore, in a comprehensive literature search that included $6615 \mathrm{NSM}$, incision types were divided into five categories: radial, periareolar/circumareolar, inframammary, mastopexy, and transareolar, and found to have nipple necrosis rates of $8.83,17.81,9.09,4.76$, and $81.82 \%$, respectively (Endara et al., 2013). Several other studies similarly corroborate these substantial differences in rates of NAC necrosis based on incision placement, with the IMF approach having the lowest rate of complication (Salgarello et al., 2010; Colwell et al., 2014; Endara et al., 2013; Chen et al., 2009). Placement of the incision in the IMF has been demonstrated to both preserve arterial supply to the NAC and to bolster the new IMF (Colwell et al., 2014; Chen et al., 2009; Margulies et al., 2005).

Regarding specific reconstructive criteria, our results demonstrate that older age had a significant relationship with skin flap necrosis $(p=0.0155)$ and overall complications $(p=0.0492)$, consistent with the findings of other authors (Komorowski et al., 2005; Dent, Small, Swistel, \& Talmor, 2014; Davies, Allan, Roblin, Ross, \& Farhadi, 2011). This is likely due to dermal thinning and the effects of age-related concomitant medical comorbidities on wound healing. In our study, prevalence of complication was significantly higher in the breast cancer side compared to the prophylactic side in patients who underwent bilateral mastectomies for unilateral cancer $(p=0.0088)$. A possible explanation for this may be inadvertent creation of thinner mastectomy flaps on the cancer side by the breast surgeon, or previous insult to the tissue on the cancer side from prior biopsy, lumpectomy, radiation, or tumor burden. Interestingly, our data demonstrated a trend of lower percentage of complication in those patients who received adjuvant chemotherapy compared to those who did not receive chemotherapy $(\mathrm{p}=0.0503)$. While chemotherapy has largely been shown to delay wound healing, Peled, et al reviewed 163 patients who underwent mastectomy and immediate breast reconstruction comparing postoperative outcomes between women who received neoadjuvant chemotherapy, adjuvant chemotherapy, or no chemotherapy. Their results demonstrated no differences between groups in terms of planned return to the operating room, expander loss, and donor-site complications, and they concluded that the timing of chemotherapy relative to mastectomy did not significantly affect surgical outcomes (Pelod et al., 2010).

Factors that exhibited trends related to increased skin flap necrosis in our study included increased excised specimen weight $(p=0.0704)$, smoking $(p=0.0726)$, and medical comorbidities including hypertension and diabetes ( $\mathrm{p}=0.0665$ ), which supports existing literature (Djohan et al., 2010; Komorowski et al., 2006; Munhoz et al., 2013). The adverse effect of increased body mass index on breast reconstruction has been previously discussed, likely due to excessive stress placed on the subdermal plexus as well as comorbidities associated with obesity (Colwell et al., 2014; Alderman, Wilkins, Kim, \& Lowery, 2002; Bailey et al., 1989; Mosahebi, Ramakrishnan, Gittos, \& Collier, 2007). A possible explanation proposed for the relationship between resected tissue weight and complication is the notion that perfusion is decreased in larger skin flaps resulting from larger breasts. Included in their study involving 500 NSM procedures, Colwell et al. noted that smoking and periareolar incisions were positive predictors for total complications, and preoperative radiation treatment contributed to an increased rate of nipple necrosis (Colwell et al., 2014). In Dent et al's results of NSM through IMF with single or two-staged implant-based reconstruction, $20.4 \%$ of patients had partial thickness or full thickness NAC ischemia The risk factors for NAC ischemia identified in their study included advanced age, increased BMI, greater breast volume, and history of diabetes mellitus. In these patients, conservative treatment failed if they also had a history of smoking, if they had undergone single-stage reconstruction, or if ADM had been utilized (Dent et al., 2014). In an evaluation of NSM via IMF in patients with previous lumpectomy, Huston et al. (2015) demonstrated an overall rate of $20.4 \%$ NAC ischemia. Conversely, they found no significant correlation between the incidence of NAC ischemia and various demographic and clinical factors including age, BMI, resection volume, prior radiation, ADM use, diabetes, or smoking history.

Of the 23 patients in our study that had radiation therapy, 14 had adjuvant therapy following mastectomy and 9 had a remote history of radiation treatment following previous lumpectomy. While the deleterious effects of radiation on tissue are well established, none of the above patients had a notably higher proportion of 
complication.

Aesthetic results of nipple-sparing mastectomy cannot be underscored. NAC reconstruction can result in asymmetry with the contralateral NAC, decreased nipple projection, nipple loss, and unsatisfactory results involving color (depigmentation), size, position, and diminished or absent sensation. Research has demonstrated that patients who undergo NAC preservation report enhanced body image, psychological adjustment, and overall satisfaction compared to women who underwent mastectomy without nipple preservation (Chen et al., 2009; Billar, Dueck, Gray, Wasif, \& Pockaj, 2011; Wellisch, Schain, Noone, \& Little, 1987; Goh, Martin, Pandya, \& Cutress, 2011). In Djohan et al.'s eight year outcome study surveying patients who underwent NSM with immediate reconstruction, a majority of patients rated appearance, symmetry, color, position, and texture as good or excellent, and $73.1 \%$ of responders stated they would definitely undergo NSM again (Djohan et al., 2010). Moreover, Didier et al's patient-reported outcome measures evaluating women with NAC preservation versus those who underwent NAC reconstruction after mastectomy, demonstrated statistically significant differences in favor of NAC preservation with regard to body image, nipple appearance, and nipple sensitivity. They similarly concluded that nipple-sparing mastectomy had a positive impact on overall patient satisfaction, body image, and psychological adjustment (Didier et al., 2009). Comparable findings have been demonstrated in patients undergoing TRAM reconstruction following NSM, where cosmetic outcomes were determined to be fair to excellent in the majority of patients. Evaluated against a baseline population, patients scored higher on average in physical functioning, vitality, emotional well-being, and general health categories (Dao \& Verheyden, 2005). Interestingly, in their experience Peled et al. found that patients with greater preoperative breast size and/or more significant ptosis reported decreased nipple satisfaction as measured by the BREAST-Q (Peled et al., 2014).

Limitations to our study include retrospective analysis and possible confounding variables associated with mastectomy such as method of flap dissection (electrocautery versus sharp dissection). While the reconstructive technique was consistent among all cases, three different breast surgeons performed the mastectomies, and the nuances of their individual surgical technique may affect flap outcome. Future study includes direct comparison to other types of incisions within our institution, use of ADMs, single-stage implant reconstruction, follow-up of our findings regarding differing results between the cancer and prophylactic breasts, and controlling for variables in breast surgeon technique. Our results are applicable to other patients who undergo nipple-sparing mastectomy via an inframammary incision and immediate reconstruction. As a major national cancer center, our database encompasses patients with a broad range of ages, ethnicities, comorbid conditions, and disease severity. It may be less applicable to institutions that routinely employ fluorescent angiography or woods lamp assessment of the mastectomy skin flaps, as they can selectively determine which patients to perform immediate reconstruction.

\section{Conclusion}

Inframammary fold incision for nipple-sparing mastectomy has been demonstrated to be oncologically sound, efficacious, and results in superior outcomes with regard to camouflaged incision and decreased complications of nipple-areolar complex or skin flap necrosis compared to other approaches in the literature. Our result of $10.6 \%$ skin flap necrosis and $8 \%$ nipple necrosis is comparable to other studies utilizing an IMF approach, and lower than those involving other incisions. Prevalence of complications was found to be significantly higher in the breast cancer side vs. prophylactic mastectomy side in patients with bilateral mastectomies, and in patients with increasing age. Factors with trends related to increased skin flap necrosis included increased excised specimen weight, smoking, or significant comorbidities. Awareness of these factors will help further delineate reconstructive criteria for appropriate patient selection.

\section{References}

Alderman, A. K., Wilkins, E. G., Kim, H. M., \& Lowery, J. C. (2002). Complications in postmastectomy breast reconstruction: two-year results of the Michigan Breast Reconstruction Outcome Study. Plast Reconstr Surg, 109(7), 2265-74. http://dx.doi.org/10.1097/00006534-200206000-00015

Bailey, M. H., Smith, J. W., Casas, L., Johnson, P., Serra, E., de la Fuente, R., ... Scanlon, E. F. (1989). Immediate breast reconstruction: reducing the risks. Plastic and reconstructive surgery, 83(5), 845-851. http://dx.doi.org/10.1097/00006534-198905000-00011

Benediktsson, K. P., \& Perbeck, L. (2008). Survival in breast cancer after nipple-sparing subcutaneous mastectomy and immediate reconstruction with implants: a prospective trial with 13 years median follow-up in 216 patients. European Journal of Surgical Oncology (EJSO), 34(2), 143-148. http://dx.doi.org/10.1016/j.ejso.2007.06.010 
Billar, J. A., Dueck, A. C., Gray, R. J., Wasif, N., \& Pockaj, B. A. (2011). Preoperative predictors of nipple-areola complex involvement for patients undergoing mastectomy for breast cancer. Annals of surgical oncology, 18(11), 3123-3128. http://dx.doi.org/10.1245/s10434-011-2008-5

Bistoni, G., Rulli, A., Izzo, L., Noya, G., Alfano, C., \& Barberini, F. (2006). Nipple-sparing mastectomy. Preliminary results. Journal of experimental \& clinical cancer research: CR, 25(4), 495.

Caruso, F., Ferrara, M., Castiglione, G., Trombetta, G., De Meo, L., Catanuto, G., \& Carillio, G. (2006). Nipple sparing subcutaneous mastectomy: sixty-six months follow-up. European Journal of Surgical Oncology (EJSO), 32(9), 937-940. http://dx.doi.org/10.1016/j.ejso.2006.05.013

Chen, C. M., Disa, J. J., Sacchini, V., Pusic, A. L., Mehrara, B. J., Garcia-Etienne, C. A., \& Cordeiro, P. G. (2009). Nipple-sparing mastectomy and immediate tissue expander/implant breast reconstruction. Plastic and reconstructive surgery, 124(6), 1772-1780.

Colwell, A. S., Tessler, O., Lin, A. M., Liao, E., Winograd, J., Cetrulo, C. L., ... Austen Jr, W. G. (2014). Breast reconstruction following nipple-sparing mastectomy: predictors of complications, reconstruction outcomes, and 5-year trends. Plastic and reconstructive surgery, 133(3), 496-506. http://dx.doi.org/10.1097/01.prs.0000438056.67375.75

Crowe Jr, J. P., Kim, J. A., Yetman, R., Banbury, J., Patrick, R. J., \& Baynes, D. (2004). Nipple-sparing mastectomy: technique and results of 54 procedures. Archives of Surgery, 139(2), 148-150. http://dx.doi.org/10.1001/archsurg.139.2.148

Dao, T. N., \& Verheyden, C. N. (2005). TRAM flaps: a reconstructive option after bilateral nipple-sparing total $\begin{array}{llll}\text { mastectomy. Plastic and reconstructive surgery, } & \text { 116(4), 986-992. }\end{array}$ http://dx.doi.org/10.1097/01.prs.0000178394.77346.53

Davies, K., Allan, L., Roblin, P., Ross, D., \& Farhadi, J. (2011). Factors affecting post-operative complications following skin sparing mastectomy with immediate breast reconstruction. The Breast, 20(1), 21-25. http://dx.doi.org/10.1016/j.breast.2010.06.006

de Alcantara Filho, P., Capko, D., Barry, J. M., Morrow, M., Pusic, A., \& Sacchini, V. S. (2011). Nipple-sparing mastectomy for breast cancer and risk-reducing surgery: the Memorial Sloan-Kettering Cancer Center experience. Annals of surgical oncology, 18(11), 3117-3122. http://dx.doi.org/10.1245/s10434-011-1974-y

Dent, B. L., Small, K., Swistel, A., \& Talmor, M. (2014). Nipple-areolar complex ischemia after nipple-sparing mastectomy with immediate implant-based reconstruction: risk factors and the success of conservative treatment. Aesthetic Surgery Journal, 34(4), 560-570. http://dx.doi.org/10.1177/1090820X14528352

Didier, F., Radice, D., Gandini, S., Bedolis, R., Rotmensz, N., Maldifassi, A., ... Lupo, F. (2009). Does nipple preservation in mastectomy improve satisfaction with cosmetic results, psychological adjustment, body image and sexuality?. Breast cancer research and treatment, 118(3), 623-633. http://dx.doi.org/10.1007/s10549-008-0238-4

Djohan, R., Gage, E., Gatherwright, J., Pavri, S., Firouz, J., Bernard, S., \& Yetman, R. (2010). Patient Satisfaction following Nipple-Sparing Mastectomy and Immediate Breast Reconstruction: An 8-Year Outcome Study [Outcomes Article]. Plastic and reconstructive surgery, 125(3), 818-829. http://dx.doi.org/10.1097/PRS.0b013e3181ccdaa4

Endara, M., Chen, D., Verma, K., Nahabedian, M. Y., \& Spear, S. L. (2013). Breast reconstruction following nipple-sparing mastectomy: a systematic review of the literature with pooled analysis. Plastic and reconstructive surgery, 132(5), 1043-1054. http://dx.doi.org/10.1097/PRS.0b013e3182a48b8a

Garwood, E. R., Moore, D., Ewing, C., Hwang, E. S., Alvarado, M., Foster, R. D., \& Esserman, L. J. (2009). Total skin-sparing mastectomy: complications and local recurrence rates in 2 cohorts of patients. Annals of surgery, 249(1), 26-32. http://dx.doi.org/10.1097/SLA.0b013e31818e41a7

Gerber, B., Krause, A., Dieterich, M., Kundt, G., \& Reimer, T. (2009). The oncological safety of skin sparing mastectomy with conservation of the nipple-areola complex and autologous reconstruction: an extended follow-up study. Annals of surgery, 249(3), 461-468. http://dx.doi.org/10.1097/SLA.0b013e31819a044f

Goh, S. C. J., Martin, N. A., Pandya, A. N., \& Cutress, R. I. (2011). Patient satisfaction following nipple-areolar complex reconstruction and tattooing. Journal of Plastic, Reconstructive \& Aesthetic Surgery, 64(3), 360-363. http://dx.doi.org/10.1016/j.bjps.2010.05.010

Gould, D. J., Hunt, K. K., Liu, J., Kuerer, H. M., Crosby, M. A., Babiera, G., \& Kronowitz, S. J. (2013). Impact 
of surgical techniques, biomaterials, and patient variables on rate of nipple necrosis after nipple-sparing mastectomy. Plastic and reconstructive surgery, $132(3), \quad 330 \mathrm{e}$. http://dx.doi.org/10.1097/PRS.0b013e31829ace49

Gulben, K., Yildirim, E., \& Berberoglu, U. (2008). Prediction of occult nipple-areola complex involvement in breast cancer patients. Neoplasma, 56(1), 72-75. http://dx.doi.org/10.4149/neo_2009_01_72

Harness, J. K., Vetter, T. S., \& Salibian, A. H. (2011). Areola and nipple-areola-sparing mastectomy for breast cancer treatment and risk reduction: report of an initial experience in a community hospital setting. Annals of surgical oncology, 18(4), 917-922. http://dx.doi.org/10.1245/s10434-010-1365-9

Huston, T. L., Small, K., Swistel, A. J., Dent, B. L., \& Talmor, M. (2015). Nipple-sparing mastectomy via an inframammary fold incision for patients with scarring from prior lumpectomy. Annals of plastic surgery, 74(6), 652-657.

Jensen, J. A., Orringer, J. S., \& Giuliano, A. E. (2011). Nipple-sparing mastectomy in 99 patients with a mean follow-up of 5 years. Annals of surgical oncology, 18(6), 1665-1670. http://dx.doi.org/10.1245/s10434-010-1475-4

Komorowski, A. L., Zanini, V., Regolo, L., Carolei, A., Wysocki, W. M., \& Costa, A. (2006). Necrotic complications after nipple-and areola-sparing mastectomy. World journal of surgery, 30(8), 1410-1413. http://dx.doi.org/10.1007/s00268-005-0650-4

Lagios, M. D., Gates, E. A., Westdahl, P. R., Richards, V., \& Alpert, B. S. (1979). A guide to the frequency of nipple involvement in breast cancer: a study of 149 consecutive mastectomies using a serial subgross and correlated radiographic technique. The American Journal of Surgery, 138(1), 135-142. http://dx.doi.org/10.1016/0002-9610(79)90253-8

Laronga, C., Kemp, B., Johnston, D., Robb, G. L., \& Singletary, S. E. (1999). The incidence of occult nipple-areola complex involvement in breast cancer patients receiving a skin-sparing mastectomy. Annals of Surgical Oncology, 6(6), 609-613. http://dx.doi.org/10.1007/s10434-999-0609-z

Margulies, A. G., Hochberg, J., Kepple, J., Henry-Tillman, R. S., Westbrook, K., \& Klimberg, V. S. (2005). Total skin-sparing mastectomy without preservation of the nipple-areola complex. The American journal of surgery, 190(6), 920-926. http://dx.doi.org/10.1016/j.amjsurg.2005.08.019

Mosahebi, A., Ramakrishnan, V., Gittos, M., \& Collier, J. (2007). Aesthetic Outcome of Different Techniques of Reconstruction following Nipple-Areola-Preserving Envelope Mastectomy with Immediate Reconstruction. Plastic and reconstructive surgery, 119(3), 796-803. http://dx.doi.org/10.1097/01.prs.0000251999.52374.09

Munhoz, A. M., Aldrighi, C. M., Montag, E., Arruda, E. G., Aldrighi, J. M., Gemperli, R., ... \& Ferreira, M. C. (2013). Clinical outcomes following nipple-areola-sparing mastectomy with immediate implant-based breast reconstruction: a 12-year experience with an analysis of patient and breast-related factors for complications. Breast cancer research and treatment, 140(3), 545-555. http://dx.doi.org/10.1007/s10549-013-2634-7

Peled, A. W., Duralde, E., Foster, R. D., Fiscalini, A. S., Esserman, L. J., Hwang, E. S., \& Sbitany, H. (2014). Patient-reported outcomes and satisfaction after total skin-sparing mastectomy and immediate expander-implant reconstruction. Annals of plastic surgery, 72, S76-S80. http://dx.doi.org/10.1097/SAP.0000000000000020

Peled, A. W., Itakura, K., Foster, R. D., Hamolsky, D., Tanaka, J., Ewing, C., ... \& Hwang, E. S. (2010). Impact of chemotherapy on postoperative complications after mastectomy and immediate breast reconstruction. Archives of surgery, 145(9), 880-885. http://dx.doi.org/10.1001/archsurg.2010.163

Petit, J. Y., Veronesi, U., Orecchia, R., Luini, A., Rey, P., Intra, M., ... \& De Lorenzi, F. (2006). Nipple-sparing mastectomy in association with intra operative radiotherapy (ELIOT): a new type of mastectomy for breast cancer treatment. Breast cancer research and treatment, 96(1), 47-51. http://dx.doi.org/10.1007/s10549-005-9033-7

Rusby, J. E., Smith, B. L., \& Gui, G. P. H. (2010). Nipple - sparing mastectomy. British journal of surgery, 97(3), 305-316. http://dx.doi.org/10.1002/bjs.6970

Sacchini, V., Pinotti, J. A., Barros, A. C., Luini, A., Pluchinotta, A., Pinotti, M., ... \& Veronesi, P. (2006). Nipple-sparing mastectomy for breast cancer and risk reduction: oncologic or technical problem?. Journal of the American College of Surgeons, 203(5), 704-714. http://dx.doi.org/10.1016/j.jamcollsurg.2006.07.015 
Salgarello, M., Visconti, G., \& Barone-Adesi, L. (2010). Nipple-sparing mastectomy with immediate implant reconstruction: cosmetic outcomes and technical refinements. Plastic and reconstructive surgery, 126(5), 1460-1471. http://dx.doi.org/10.1097/PRS.0b013e3181ef8bce

Salibian, A. H., Harness, J. K., \& Mowlds, D. S. (2013). Inframammary approach to nipple-areola-sparing $\begin{array}{llll}\text { mastectomy. Plastic and reconstructive surgery, } & 132(5), & 700 \mathrm{e}-708 \mathrm{e} .\end{array}$ http://dx.doi.org/10.1097/PRS.0b013e3182a4d64f

Smith, J., Payne, W. S., \& Carney, J. A. (1976). Involvement of the nipple and areola in carcinoma of the breast. Surgery, gynecology \& obstetrics, 143(4), 546-548.

Spear, S. L., Hannan, C. M., Willey, S. C., \& Cocilovo, C. (2009). Nipple-sparing mastectomy. Plast Reconstr Surg., 123, 1665-1673. http://dx.doi.org/10.1097/PRS.0b013e3181a64d94

Spear, S. L., Willey, S. C., Feldman, E. D., Cocilovo, C., Sidawy, M., Al-Attar, A., ... \& Nahabedian, M. Y. (2011). Nipple-sparing mastectomy for prophylactic and therapeutic indications. Plastic and reconstructive surgery, 128(5), 1005-1014. http://dx.doi.org/10.1097/PRS.0b013e31822b6456

Stolier, A. J., \& Wang, J. (2008). Terminal duct lobular units are scarce in the nipple: Implications for prophylactic nipple-sparing mastectomy. Annals of surgical oncology, 15(2), 438-442. http://dx.doi.org/10.1245/s10434-007-9568-4

Verma, G. R., Kumar, A., \& Joshi, K. (1997). Nipple involvement in peripheral breast carcinoma: a prospective study. Indian journal of cancer, 34(1), 1-5.

Vlajcic, Z., Zic, R., Stanec, S., Lambasa, S., Petrovecki, M., \& Stanec, Z. (2005). Nipple-areola complex preservation: predictive factors of neoplastic nipple-areola complex invasion. Annals of plastic surgery, 55(3), 240-244. http://dx.doi.org/10.1097/01.sap.0000171680.49971.85

Wellisch, D. K., Schain, W. S., Noone, R. B., \& Little III, J. W. (1987). The psychological contribution of nipple addition in breast reconstruction. Plastic and reconstructive surgery, 80(5), 699-704. http://dx.doi.org/10.1097/00006534-198711000-00007

Wijayanayagam, A., Kumar, A. S., Foster, R. D., \& Esserman, L. J. (2008). Optimizing the total skin-sparing mastectomy. Archives of Surgery, 143(1), 38-45. http://dx.doi.org/10.1001/archsurg.143.1.38

\section{Copyrights}

Copyright for this article is retained by the author(s), with first publication rights granted to the journal.

This is an open-access article distributed under the terms and conditions of the Creative Commons Attribution license (http://creativecommons.org/licenses/by/3.0/). 